\title{
The Lived Experiences, Perceptions, and Considerations of Patients After Operable Lung Cancer Concerning Nonparticipation in a Randomized Clinical Rehabilitation Trial
}

Schønau, Mai Nanna; Hansen, Mette; Ulvestad, Sigrid; Sommer, Maja Schick; Pedersem, Jesper Holst; Missel, Malene

Published in:

Qualitative Health Research

DOI:

$10.1177 / 1049732319886564$

Publication date:

2019

Document Version

Peer reviewed version

Citation for published version (APA):

Schønau, M. N., Hansen, M., Ulvestad, S., Sommer, M. S., Pedersem, J. H., \& Missel, M. (2019). The Lived Experiences, Perceptions, and Considerations of Patients After Operable Lung Cancer Concerning

Nonparticipation in a Randomized Clinical Rehabilitation Trial. Qualitative Health Research, 30(5), 760-771 . https://doi.org/10.1177/1049732319886564

\section{General rights}

Copyright and moral rights for the publications made accessible in the public portal are retained by the authors and/or other copyright owners and it is a condition of accessing publications that users recognise and abide by the legal requirements associated with these rights.

- Users may download and print one copy of any publication from the public portal for the purpose of private study or research.

- You may not further distribute the material or use it for any profit-making activity or commercial gain.

- You may freely distribute the URL identifying the publication in the public portal.

Take down policy

If you believe that this document breaches copyright please contact rucforsk@kb.dk providing details, and we will remove access to the work immediately and investigate your claim. 
The Lived Experiences, Perceptions and Considerations of Patients after Operable Lung Cancer Concerning Non-Participation in a Randomized Clinical Rehabilitation Trial

\begin{abstract}
This study explored the lived experiences, perceptions and considerations of individuals who declined participation in a randomized clinical trial involving exercise rehabilitation after surgery for lung cancer and helps illuminate why this group is difficult to recruit and retain. An interpretive phenomenological approach was applied comprising interviews with 15 individuals who did not wish to participate in the trial. The findings shed light on a discrepancy between their freedom to act and make decisions, and the limitations of having to act in a certain way. The participants found themselves in a gray area between a healthy life and a good life, as influenced by societal norms and taking responsibility for one's own health and rehabilitation. When including patients in rehabilitation after lung cancer, having insight into the underlying narrative on values and the good life, priorities in daily life, social context and the norms embedded in people's self-understanding is crucial.
\end{abstract}

\title{
Keywords
}

Lung cancer; surgery; physical exercise; qualitative; reflective life-world research; phenomenological; non-participation 


\section{Introduction}

Patients with lung cancer are difficult to recruit and retain in research projects. This was also the case in a recent randomized clinical trial (RCT) that recruited patients with operable lung cancer for exercise rehabilitation after surgery. We were curious about why they did not wish to participate in the study despite the fact that the Danish health authorities widely recommend doing so and the fact that patients with cancer who participate in physical exercise have achieved good results in the past. Our aim was to find out what was going on in their lives and to identify the thought processes behind their decision not to participate. Understanding these issues is essential to comprehending their world to ensure that as many patients as possible can benefit from exercise rehabilitation in the future.

\section{Background}

Lung cancer, one of the most common cancers, is associated with the highest mortality rate worldwide (Rasmussen \& Jakobsen, 2013). For patients diagnosed with non-small cell lung cancer (NSCLC), surgery is the treatment of choice, followed by adjuvant oncological treatment (30\%). Patients diagnosed with NSCLC are 65 years old on average and receive extensive surgical and oncological treatment that may have consequences, such as decreased physical capacity, dyspnea, fatigue, restlessness, loneliness and depression. Symptoms, which may be long-lasting or persistent, reduce the patient's functioning, quality of life and ability to restore and maintain an active everyday life (Handy et al., 2002; Oksholm et al., 2015; Sarna et al., 2008).

Exercise has been introduced to improve physical capacity and quality of life and to reduce the symptoms and side effects of treatment in patients with other cancer diagnoses (Adamsen et al., 2009; Midtgaard et al., 2011; Mishra et al., 2012). Systematic reviews report that 
exercise interventions are safe and feasible for patients with operable lung cancer and indicate that they benefit exercise capacity, symptoms and quality of life (Cavalheri et al., 2014; Crandall, Maguire, Campbell, \& Kearney, 2014; Granger, McDonald, Berney, Chao, \& Denehy, 2011; Sommer et al., 2018a). Exercise training has also been associated with improved muscle strength, a reduction in postoperative complications and shorter hospitalization (Arbane, Tropman, Jackson, \& Garrod, 2011; Kenny et al., 2008). Against this background, an RCT was developed to investigate the efficacy of a postoperative exercise intervention for patients after lung cancer surgery (initiated as early as two weeks after surgery) (Quist et al., 2018). This 12-week exercise intervention involved 24 group sessions and took place in a community-based training center. The intervention comprised two 60-minute weekly sessions with supervised strength and cardiovascular exercise. Physiotherapists and a cancer nurse specialist supervised the sessions, complying with recommendations of the American College of Sports Medicine (Garber et al., 2011). Before the RCT was initiated, a feasibility study was conducted demonstrating a significant improvement in global quality of life, mental health and emotional well-being from time of diagnosis until one year after resection in patients with NSCLC participating in the exercise intervention (Sommer et al., 2018b; Sommer et al., 2016).

Due to the feasibility study's promising results, considerable efforts were made to enlist participants for the RCT. Despite these efforts, only 53\% of eligible participants consented to participate in the exercise intervention (Quist et al., 2018). A study by Bade et al. (2015) indicated that possible barriers for participating in exercise interventions are high symptom burden, the side effects of treatments and high prevalence of comorbidity. The literature also highlights the problems associated with trial participation for lung cancer patients (Coups et al., 2009; Jones, Eves, Spasojevic, Wang, \& Il'yasova, 2011), although few studies examine in-depth why these patients refused to participate in clinical trials. As a result, the purpose of 
this qualitative study was to explore perceptions and considerations of non-participation in the RCT called Perioperative Rehabilitation in Operable Lung Cancer Patients (PROLUCA), but also the patients' lived experiences of their own life situation, health and need of support.

\section{Methods}

\section{Philosophical Underpinnings}

The study's philosophical approach was grounded in phenomenology, creating an epistemological stance for exploring first-person accounts of what it is like to live with and be treated for operable lung cancer after being invited to, but declining to participate in, an exercise intervention. Reflective lifeworld research, which is a descriptive, interpretive phenomenological research approach developed by Dahlberg et al., (Dahlberg, Dahlberg, \& Nytröm, 2008), is the underlying inspiration for this study and is primarily based on the phenomenology and hermeneutics of philosophers such as Husserl, Heidegger, MerleauPonty and Gadamer. The aim of reflective lifeworld research is to describe the essential meaning of a phenomenon, i.e., the meaning structures of the phenomenon. This approach has been commonly applied to explore a variety of health situations (Bremer, Dahlberg, \& Sandman, 2009; Mushkin, Band-Winterstein, \& Avieli, 2018; Sundler, Dahlberg, \& Ekenstam, 2009).

In reflective lifeworld research, the researcher should have an open-minded attitude throughout the entire research process to get close to the phenomenon without taking any meaning for granted. This includes a process in which the researcher tries to suspend understandings to go beyond the natural attitude of taken-for-granted understanding. Dahlberg et al. (2008) called this process bridling, which means adopting an open, alert attitude to the phenomenon and being reflective. Consequently, the point is to see the world 
differently by adopting an open, explorative attitude and to be surprised by new meanings that arise along the way, rather than forcing the material to fit one's own ideas. The process of bridling is, as such, about slowing down the evolving understandings and includes restraining one's personal beliefs, theories and preconceptions of the phenomenon that otherwise could confound understanding.

In reflective lifeworld research, the analysis can be either descriptive or interpretive (Dahlberg, Dahlberg, and Nytröm, 2008). In the interpretive approach, the analysis facilitates the discovery of meaning through an intertwined process of description and interpretation. In the present study, we adopted a scientific interpretational attitude towards the data with the intention of creating a rich, deep account of the phenomenon under study, i.e., to achieve an uncovering rather than solely an accurate analysis of the participants' descriptions. Thus, interpretation was applied to gain deep insight into the reality of the participants. According to the hermeneutic tradition, understanding the conditions of our lifeworld always involves interpreting words and actions. Language, including texts, contains connotations that can only be approached through a process of interpretation, a phenomenon that Gadamer (2004) also described. In reflecting on the meaning and significance of the participants' lived experiences, we strived to go beyond preconceptions to the thing itself (Dahlberg, Dahlberg, and Nytröm, 2008). Through the analysis, we went from the particular to the general, looking through the examples to the general essence.

\section{Recruitment of Participants}

Adult ( $\geq 18$ years) individuals with a biopsy-proven diagnosis of NSCLC and scheduled for surgery with curative intention at the department of thoracic surgery at a university hospital were invited to participate in an RCT testing the efficacy of early initiated postoperative 
exercise. See Sommer et al. (2014) for further details on inclusion and exclusion criteria in the protocol for the exercise intervention. Participants in the present study on patients who declined to participate in the exercise intervention (non-participants) were purposefully sampled (Crabtree \& Miller, 1999) and recruited from the group of people who were eligible for the exercise intervention but who did not wish to participate. Fifteen non-participants consented to participate in qualitative interviews on their perceptions and considerations for not participating in the PROLUCA RCT, as well as their lived experiences of their own life situation, health and need of support. None of the eligible individuals declined to participate in the interview study. Participants included in this qualitative study had a mean age of 68 years (range 48-84). Nine participants were male and six female. Four participants were living alone, while 11 were married. Most of the participants, 10 individuals, were retired.

\section{Ethics}

The study adhered to the ethical requirements of the Helsinki Declaration. Participants received written and oral information about the study and were informed that they were free to withdraw from the study at any time without any implications for their further treatment. The participants were informed orally and in writing that their data would be treated confidentially and that any form of data that could be linked to the participants would be pseudo-anonymized. Sensitive recruitment of individuals who were asked but did not wish to participate in a clinical trial is important in building relationships and in establishing participation in interviews. These ethical issues were considered of particular importance when approaching and including individuals for the interview study. The study was approved by the Ethics Committee of the Capital Region of Denmark (file no. H-3-2012-028) and by the Danish Data Protection Agency (2007-58-0015). 


\section{Data Collection}

Individual interviews were conducted with eligible participants 12-28 months (mean 21) after they had undergone a lung cancer operation but declined to participate in an exercise intervention (Crabtree \& Miller, 1999). The participants were approached by the chief surgeon (JHP) and asked to participate in interviews. When they agreed to participate, an appointment for the interview was scheduled. The interviews were conducted by two graduate students (MH and SU), both of whom had clinical and interview experience guided by an experienced qualitative researcher (MM). Interview topics included patients' lived experiences of any changes in health since the operation, social relationships, support received from the healthcare system and participation in other rehabilitation initiatives, physical activities or exercise. Also asked to narrate their daily life experiences since the operation, participants were gently requested to describe their perceptions, considerations and the barriers that led to declining to participate in the RCT exercise intervention. Each interview concluded with the question, "Given your experiences, can you think of any support that would have been helpful for you?" Interview topics were developed based on curiosity regarding how the participants managed their daily life and health because previous research indicates that this patient population might experience physical and emotional problems after lung cancer and a decline in health and health-related quality of life (Cavalheri et al., 2014; Handy et al., 2002; Missel, Pedersen, Hendriksen, Tewes, \& Adamsen, 2016; Quist et al., 2018). Another main topic included the considerations the patients had when declining participation in the intervention. Table I presents the interview guide. The interviews, which lasted 40-90 minutes and were recorded and transcribed verbatim, emphasized listening to the participants. The goal was not to limit or distort the information they provided (Crabtree \& Miller, 1999; McCance, McKenna, \& Boore, 2001). Openness, curiosity and sensitivity played an important role while carrying out the interviews. As such, our preconceptions about the patient group, exercise and health played a role in the shaping 
of the interview questions; however, during the interviews, we tried to bridle these preconceptions by adapting an attitude of openness to the participants' lifeworld, as described above. According to Dahlberg et al. this approach requires a willingness to be sensitive to the phenomenon and to the complexities of the lifeworld (Bremer et al., 2009; Dahlberg, Dahlberg, and Nytröm, 2008).

\section{Data Analysis}

The analytical process followed Dahlberg et al.'s (2008) reflective lifeworld research approach, which recommends using a circular process that involves four phases. The first phase includes gaining an overall sense of the data followed by three phases that involve probing more deeply. The aim of the analysis, which was to describe the essential structure of the phenomenon under study, involved a search for the invariant structure of meaning; in other words, the meaning that constituted the essence. The analysis began with repeated readings to become immersed in the descriptions and to acquire an overall understanding of the interview texts. The second phase began after the overall impression was obtained and involved an analysis of each interview to discover the meaning from the participants' point of view. To determine the meaning, the individual texts were divided into units of meaning comprising small text segments and the analysis involved asking questions like: "What is being said?", "How is it said?" and "What is the meaning?" In the third phase, meanings that appeared to be linked were clustered together to ascertain the presence of a pattern and to provide an overview of essential meanings and their interrelated structure. Subsequently, tentative interpretations of the emerging meanings were divided into clusters of understanding that mirrored their interrelationships. The interpretation of subparts was compared with interpretations of the whole. The researchers moved repeatedly back and forth 
between the parts and the whole to determine whether or not there were any discrepancies between the understanding of the parts and that of the emerging interpretations.

Finally, the fourth and last phase involved an active, open reflection on the data and an elaboration of the meaning that had emerged. All tentative interpretations deemed valid were compared with each other to arrive at a main interpretation for all data of general importance. Thus, the aim of this phase was to synthesize the clustered units of meaning to represent a new whole. We discussed the analysis several times among ourselves, simultaneously questioning our preunderstanding to minimize its negative influence on the emerging description of the phenomenon, as described by Dahlberg et al. (2008). The essence of the phenomenon of perceptions and the considerations behind non-participation in an exercise intervention and participants' lived experiences of their own life situation, health and need of support are presented below as one general meaning structure with three constituents. Interview quotes are given to provide examples of explicated meaning. The examples reveal the participants' ways of being, thinking and acting in the world that shed light on what is known but covered over. These examples are presented throughout the findings, along with the researchers' interpretations, while participants' verbatim quotes are used to illustrate the themes. In the following, the findings will be presented and discussed at the level of the individual and of society.

Subsequently, a more profound understanding of the findings will be discussed according to selected aspects of various theories. Pondering the findings and the interviews in relation to theory may give the impression that theory controlled the selection of empirical data but this was, in fact, not how we proceeded. Throughout the entire research process, we were aware of ensuring that the empirical data instead controlled the selection of theory.

\section{Findings}


The following section presents the essential meaning within the three constituents derived from the analysis and the interpretation of the interviews, which describes and explicates nonparticipation in exercise rehabilitation.

\section{Gray Area between a Healthy Life and a Good Life}

The participants' previous experience with exercise was shown to determine how much they were able to associate exercise with something important and meaningful. In the case of participants who had exercised previously, one important parameter was being able to get themselves going again. A female participant, age 65, stated: "It took maybe ... four months. Yeah, about four months before I exercised and got my fitness level back up at home".

For this woman, who was used to doing fitness before the illness and surgery, like other participants in our study, it became a way to take independent action and to regain control and a sense of agency over her own life after illness. For this reason, these participants declined participation in a structured exercise program determined by healthcare professionals. However, these participants experienced physical limitations after surgery, which meant that they had to adapt their exercise routine as one male participant stated: “Before having surgery, I used to go running. I still do - I'm not quite as fast, but I've just had to take that into account. There are some things I might not be able to get back up to exactly the same level as before, but at least I can run."

This man experienced troubles with breathing after the surgery, but his previous running experience compelled and helped him get started again. For participants with an exercise history, being physically active is part of their individual identity and can be a source of satisfaction. By contrast, little or no experience with exercise can mean that the participants failed to identify any direct link between exercise rehabilitation and purpose and meaning in 
their lives. For these participants, exercise was not a suitable activity that gave their lives meaning, which is why they did not necessarily give the activity the highest priority. A 78year-old male participant told us: "It's the same as before - I don't exercise". The drive for this man was to maintain daily life as it was before illness and surgery, where he enjoyed watching tv and had never experienced a desire to exercise. The participants became clear about how they wanted to prioritize their activities when they were presented with a rehabilitation program in the period after surgery. They realized what gave them the greatest satisfaction and what gave them meaning in their lives. Some participants prioritized work, and time for physical exercise did not fit in with this:

You know, it just wasn't appropriate in my case [participating in rehabilitation] because I had to go back to work. And I had to decide whether I should use the additional time. I didn't think I could find time for it. It was a question of prioritization on my part and about returning to normal life in another way. This 64-year-old male participant started to work full time six weeks after surgery. He prioritized his job higher than participating in the rehabilitation program.

The participants thus described how it was meaningful to prioritize according to what was needed to live "a good life" or a meaningful one after their illness. A good life for the participants consisted of activities that had inherent value, i.e., things they did for their own sake and which they chose to do, not just things they did to achieve something else, e.g., participating in the rehabilitation program, even though doing so could be considered as a healthy life, as described by this female participant:

My everyday life is about getting up in the morning and drinking my coffee, like everybody else, I guess. Then it's primarily friends and my boyfriend who fill my life, and also my kids. They are 20 and 23. So I have a lot to do. Having cancer sets a lot of thoughts in motion, and then ... I think that our awareness of 
what is really valuable in life has been sharpened. And of what really doesn't matter. I know I should be exercising, maybe that could do something good for my health, but I think other things are more valuable for me now.

It can be difficult for participants to relate to exercise if their own values or identities revolve around something else. The participants also described their view of physical exercise. For some, exercise involved everyday activities such as gardening, going for walks or doing housework: "Well, you know, I go for walks and I work in the yard," explained an 84-yearold male participant. For participants like him, the rehabilitation program's structured sessions, with supervised strength and intensive cardiovascular exercise, would interrupt usual daily activities, making them a reason to decline participation.

Furthermore, the participants also felt torn between a desire to take part in a rehabilitation program and not having the energy to do so. A 72-year-old male participant stated: "I didn't really feel I had the energy for it [exercise] back then and it took up quite a lot of time and didn't really fit in with our lives ..." This man subsequently made the reflection that he probably would have participated if the program had been offered a longer time after surgery. This ambivalence might arise from the fact that a change in behavior and participation in rehabilitation activities are not simply about changing behavior patterns, but also one's general lifestyle. The participants ultimately possibly felt insecure, uncomfortable or troubled in terms of this kind of change. As a result, encouraging participants to act differently and to start exercising may be more unmanageable and involved than is readily apparent, hindering non-participation. This analysis illustrated how some individuals felt that the exercise rehabilitation project represented outside interference, which they fought against and resisted: 'I've never felt like it [exercise], and my daily life is just how it was before; I haven't changed a thing. I'm not the only one who feels that way!" insisted a 77-year-old male participant. 


\section{Under the Influence of Society - Physical Exercise as a Norm}

The participants mentioned the importance of being physically active to be in good health, stating that they recognized the benefits of exercising - not just for the sake of fitness and strength, but also health. Exercise is thus associated with health, but at the same time it might be an expression of societal norms about the productive and performing body. The participants' descriptions come across as an embedded norm about exercise being something you ought to do, as expressed by a 56-year-old female participant: "I admit that I don't exercise as much as I ought to," while another male participant stated: "Sure, I suppose I ought to go on more walks." Our analysis shows that participants who turned down rehabilitation, and who do not otherwise engage in exercise of their own accord, do not experience themselves as living up to the norm of being physically active. These participants thus break with the values, expectations and guidelines for common behavior that are rooted in society, namely that exercise leads to better health. Thus, these participants experience the feeling that they ought to act differently, and they talk about the expectation that they should be physically active. This can be felt as pressure from the outside world. As one 68-year-old male participant explained: "Many of my friends think I should start exercising, so I kind of feel under pressure to a certain extent". This pressure can be a burden: "I should do more, but I don't feel up to it," explains one female participant. The participants experienced internal pressure from the embedded norm that exercising is a must, but also external pressure from the outside world and their social network. This pressure, combined with a guilty conscience, can prevent them from acting in harmony with their own values and basic narrative about a good life. The ingrained norm can overshadow the participants' usual understanding of their lives, leading them to feel inadequate in their attempts to take care of themselves after lung cancer. An 84-year-old male participant stated: “I wasn't interested in the rehabilitation 
program and declined because I didn't want to commit myself to such a thing. But then I had to promise the doctor that I would go for walks every day."

Physical exercise had never been part of this man's daily life and he could not see himself using an exercise bike in a group with other former patients. He did not feel, however, that turning down the offer to participate was acceptable. Thus, one possible reaction is that participants may feel that their self-understanding and identity are under pressure, and they may lose self-confidence and begin doubting whether they are able to manage their lives properly.

The participants' individual prioritization not to participate, whether due to a lack of energy or prioritizing work, might mean that they are breaking with social norms about the right thing to do. But it means they are independently defining what a good life means for them, making choices and priorities that feel right for them individually as one 56-year-old female participant stated: "I've never liked exercising, all those sports, running and fitness training. It's not for me. I know everybody talks about how necessary it is for your health, but I feel good." Declining to participate requires the participants to actively downplay the rules and norms emphasizing the necessity of physical exercise in society, and which are the focus of the rehabilitation program.

Some participants said that despite not living up to the norms about physical exercise, they actually felt quite good. A 69-year-old male who has never exercised regularly explained: "I go for walks, but probably not often enough, but I still feel good.” For the participants, living up to the social norm of exercising does not necessarily equate with feeling good. Some participants independently manage to create a life and a normal everyday existence, which 
they feel creates a good life for them, despite the norms of society. An 84-year-old female participant stated: “I don’t like exercising, and I have never exercised, but I like reading novels, magazines and so on. I like my life as it is, and I don't want to change a thing." As such, these participants do not personally feel that they have a need to participate in a rehabilitation program.

\section{Health and Exercise - A Personal Responsibility}

The participants talked about various ideas concerning how much responsibility they had for their own health, including physical exercise. Many of them said that it was important for them to independently take the initiative to be physically active. An 82-year-old participant stated: "I go for short walks, not as much as before, but I walk as much as I can." While trying to recover from lung cancer, this woman also experienced other comorbidities, such as serious back pain, shortness of breath and tiredness, which, combined, influenced her possibilities for being active. Even though the participants declined to participate in the exercise rehabilitation, the analysis showed that many of them believed they were personally responsible for exercising, as illustrated by this statement from a 67-year-old female participant: "I knew I had to do something by myself to get going again, so I started walking. I wanted my old life back again, so I thought, the more I get going and am in the process of exercising, the faster I can do the things I want to do."

The participants did not mention that they expected society to offer them a rehabilitation program or healthcare professionals to help them. This shows that participants had a tendency towards taking individual responsibility for their health, indicating that they felt able to act and make autonomous decisions, and thus able to make conscious choices. This feeling of personal responsibility meant that they did not expect the healthcare system to provide their 
rehabilitation, placing, as our analysis shows, moral responsibility for activities related to their own health on their own shoulders. This caused some participants to feel guilty if they failed to live up to that responsibility as one male participant explained: "I' $m$ not in great condition, and certainly not right now, but that's mostly my own fault."

Thus, health, including exercising, is seen as a matter of personal responsibility, and the analysis showed that many participants have a desire to be physically active. One female participant, age 50, said, for example: "You need to go to work to get paid, and similarly you need to get out of bed to get love". For this woman, getting out of bed could be interpreted as being physically active, but it could also be taken as a symbol of taking action and doing something yourself and, as a result, being rewarded by those around you. The participants strived to be active rather than becoming passive victims of the illness. Thus, the analysis illuminates how the participants felt responsible for their own health, with all the self-blame that may imply.

The analysis indicated that the participants had their own ideas in terms of what they want to be in relation to health and exercise and that they are trying to pursue this idea as best they can. One 59-year-old male participant said: "I do the yard and the house, and I do the shopping and I walk to the library. I move a lot. We have a large lawn, so there's exercise there for me," which he explained was also the case prior his illness and surgery. This does not necessarily mean that the participants know about the advantages of physical exercise, but it does show that they are aware of social norms and recommendations for physical exercise. The everyday lives of the participants showed them that they can exercise independently, providing a reason to choose not to participate in the program. The analysis also showed that not everyone can take personal responsibility for exercising on their own. This begs the 
question as to whether human beings can, in general, make autonomous choices and then follow through on them. Thus, participants might experience a sense of personal responsibility for exercising but also difficulties in making and acting on conscious choices, both regarding their own effort to exercise and the considerations behind declining to participate in the rehabilitation trial.

\section{Discussion}

Poor enrollment in clinical trials has been and still is an important issue in rehabilitation studies. The enrollment rate of 53\% reported in the PROLUCA study (Quist et al., 2018) is quite similar to previous exercise oncology trials on patients after treatment for lung cancer (Arbane et al., 2011; Granger et al., 2011; Jones et al., 2011; Missel et al., 2015). Careful analyses of perceptions, considerations and attitudes of non-participation in rehabilitation are necessary to make significant progress in supporting people after lung cancer surgery. In this article, we illuminated some perspectives on what might be at stake for people who do not wish to participate in a clinical exercise rehabilitation trial, as seen from these individuals' point of view.

\section{The Good Life}

The analysis and interpretation illustrated how the participants found themselves in a gray area between a healthy life and a good life. The participants described how their exercise history, or lack of it, affected whether they could see a link between exercise rehabilitation and purpose and meaning in their lives, which was one of the key elements when declining participation. Exercise is described in the literature, primarily from Western culture, as the formula for a healthy life, just as epidemiological studies have shown that daily physical activity or regular exercise is beneficial to health, protecting against various physical and mental illnesses and disorders (Gerber \& Pühse, 2009). However, the image of a good life 
being a healthy life does not necessarily coincide with the participants' perceptions; for the participants, life is something that feels good rather than being thought of as good.

The phenomenon of a good life has been discussed by philosophers since Aristotle, and there are indications that it is a matter of values that are more deeply rooted than what statistical studies can express as numbers and figures. In several studies within exercise oncology and lung cancer surgery, primary outcomes are often related to measurable benefits of health and quality of life (Cavalheri et al., 2014; Crandall et al., 2014; Granger et al., 2011), whereas this study illustrated how certain values and perceptions of a good life play a role. According to Aristotle (2004), a good life for people consists of more than just physical and material goods. A good life is made up of practices or activities which have intrinsic value, namely things done for their own sake and not just to achieve an external goal, such as health. Thus, a change in behavior, such as participation in an exercise trial, can lead to a discrepancy between health and the individual participant's expectations regarding a good life for themselves, perhaps bringing a loss of meaning if exercise does not have intrinsic value for that particular participant. On the other hand, it is easier for participants who previously associated exercise with value and satisfaction to link it with meaning and expectations about a good life, as other studies also report (Kampshoff et al., 2014; Ormel et al., 2018).

According to Bandura's social cognitive theory, a person's experience with a certain behavior plays a significant role in whether they believe that that behavior can be demonstrated in practice (Bandura, 2004). In other words, if the individual has had good experiences with exercise, the probability that they have a high degree of self-efficacy in relation to similar lifestyle changes is greater than if the opposite is the case. Furthermore, according to Bandura, much of our behavior is also influenced by observations we make during our lifetime. This means that we assume some of the behavior displayed by our social network. Thus, throughout our lives, with our personal experiences, observations of others' 
experiences and society's messages about health, we as individuals develop a partially subconscious attitude toward things such as exercise, and this plays a significant role in situations when exercise becomes relevant, as this study illustrates. Similarly Rogers and Tudor-Locke described the importance of how much a given new idea, such as physical exercise, is experienced by people as fitting in with their existing habits, attitudes and norms in that area (Martinez, Oberle, \& Nagurney, 2013; Rogers \& Tudor-Locke, 2006). If this is not the case, they might see a structured exercise program as problematic and difficult to integrate into their everyday lives. It could be said that behavior that is not compatible with existing norms and attitudes in an area of life creates a dissonance with regard to these norms and attitudes, with the new behavior casting doubt on some of the basic assumptions on which the individual's life is built. This dissonance, which is clearly reflected in the present study, occurs when participants felt ambivalent, uneasy and insecure about opting not to participate in the rehabilitation program.

\section{Influence of Society}

This analysis illustrated that society influenced how the participants acted regarding participation or non-participation in rehabilitation. Irrespective of whether the participants accept or declined to participate, exercise is experienced as a norm and an obligation. Consequently, participants may feel pressured to be physically active and perhaps develop a guilty conscience if they fail to live up to this norm. At the same time, however, the participants had the option to take the initiative and engage in exercise, even if they said no to the trial. These participants believed that they did not need the program. Studies have demonstrated that the relationship between norms and behavioral intentions is moderated by assorted variables. Real and Rimal (2005) identified three cognitive processes: injunctive norms, group identity and outcome expectations as significant moderators in the relationship between norms and intention. As such, the relationship between norms and behavior is not 
simple. For the participants in the present study, norms are experienced as an obligation and something one ought to do to adhere in terms of health advice.

The social norm of getting started and being active as soon as possible entails a risk in that it can impose a choice on the participants too early on in their reflections about what action to take. It might also interfere with the participants' priorities. People have good reason to mull over the various alternative situations they face in the various phases of life, since life situations change. Practical reasoning most often takes the form of an internal dialogue (and dialog with others) over a period of time (Hoffmann, 2008), a process that is overseen in the tradition behind society's predominant focus on decision theory (Levin, Milgrom, \& Rangel, 2004) in the health promotion paradigm, which is concerned with the end result and only the final stages up to our choices and decisions. The dialogical is completely ignored, as is the fact that practical decision-making takes place over a prolonged period of time, which, moreover, reaches back in time (de Sousa, 2003; Hoffmann, 2008). De Souza (2003) emphasized that the fact that people continually mull over and weigh up benefits in relation to one another is a feature of life, and also that benefits appear in juxtaposition with something else: what is beneficial in one context is not necessarily beneficial in another (de Sousa, 2003). The participants' interpretations of what is right and beneficial for them regarding the considerations behind participation in the rehabilitation program therefore do not represent a stable, clear-cut process, but involve interpretation, where benefits are compared with one another.

Thus, attention should be put on more than just how healthcare professionals provide information about participation in exercise rehabilitation trials, but also on when and in what context. The point of departure should be how people experience autonomy in terms of 
making the choices that create a good life for them, while also being informed about the advantages of taking part in exercise rehabilitation, without this being felt as pressure. Equally, timing and the time dimension should also be part of the picture. For each individual patient, healthcare professionals should establish what enables that particular patient to better understand and reflect on the roles life gives them, what value and social framework the individual is part of and also how this framework should develop and unfold.

\section{Personal Responsibility}

Exercise and physical activity, also known as new public health, play a major role in Western society (Petersen, 2000) and are the most documented and acknowledged way to stay healthy and regain health (Pedersen \& Saltin, 2015). The fact that exercise can prevent some illnesses and their consequences makes it a professional goal to have patients increase their level of physical activity. This may be challenging, however, even when patients recognize their responsibility for their own health, as demonstrated in our analysis. The present study shed light on how the participants experienced having responsibility for their own health and rehabilitation, an issue also explored by other studies (Henshall, Greenfield, \& Gale, 2017). It is debatable, however, whether individuals can truly have personal responsibility for their

own health. This study, for example, indicated that taking personal responsibility for making decisions about participating in an exercise rehabilitation trial is not carried out entirely autonomously. Other studies indicate that, in terms of health, lifestyle and exercise (Diderichsen, Andersen, \& Manuel, 2011), one’s socioeconomic status plays a role. A consistent connection has been demonstrated between people's social position in society and their health, particularly in terms of education, income and cohabitation status. These inequities in health arise because of the circumstances in which people grow up, live, work and age, and the systems put in place to deal with illness. Political, social and economic 
forces shape the conditions in which people live and die (World Health Organization, 2018), which is why making completely independent, voluntary choices about one's own health and rehabilitation may be impossible. Petersen and Lupton (2000), who have examined central assumptions concerning new public health, pointed out that the area has its own rhetoric and objectives that rely on a traditionally modernist, science-based approach in dealing with health. This approach, the authors argued, can be viewed as a new morality system in a society where individuals are expected to take responsibility for caring for their bodies by embracing various preventive actions. One possible consequence, however, is that new public health may serve to make moral judgements that involve casting blame on certain groups of people or, in the case of the present study, a judgement about the morality of the participants' decision to decline to participate in an exercise rehabilitation trial.

In today's healthcare system, there is an underlying assumption that participants want to take responsibility for their own lives, to work efficiently towards improving their health, and that they can help themselves (Petersen, 2000). Furthermore, good health is seen as a basic precondition for people's freedom to be able to live the life they value (Anand, 2002). Studies show that a window of opportunity or a teachable moment for lifestyle changes can occur; for example, a cancer diagnosis is a particularly important time point for making changes in unhealthy lifestyle choices, such as smoking and physical inactivity (Demark-Wahnefried, Aziz, Rowland, \& Pinto, 2005; Mills \& Pierce, 2008; Moller et al., 2013). The expectation is that, through this window of opportunity, healthcare professionals have an opening to deliver a message, support and advice about the best lifestyle changes and interventions, in such a way that patients subsequently understand and are motivated to carry out the changes (Mills $\&$ Pierce, 2008). Despite the benefits of supporting people at this particular moment, a picture of the rational patient who self-manages their condition might be accompanied by an underlying narrative of responsibility that implies that, if we are unable to self-manage our 
health and well-being, then we are not measuring up at a very personal level (Horrocks \& Johnson, 2014). This perspective of lifestyle changes is strongly influenced by certain theories of health behavior, where emphasis is put on behavior as individually driven and cognitively motivated, with health beliefs framed as the favored mechanisms to target to bring about changes leading to improved health (Bell, 2012). The findings in the present study showed that participants were in a gray area between a healthy life and a good life but also under the influence of society. From this perspective, it may be beneficial and necessary to take on a more socially situated approach to lung cancer patients' rehabilitation wishes, possibilities and needs. The analysis of the participants' voices in the present article recognizes that health is created beyond the individual level.

\section{Clinical Implications}

As healthcare professionals, it is important to be aware of the ethical implications of what we do and how we inform or advise patients on rehabilitation after, e.g., lung cancer. The ends may justify the means; however, maintaining a reflective approach to the patients is crucial in order to be aware of and address the individual person's underlying narrative of values and the good life, their balance between priorities in daily life, the social context and relationships in which they live their life and the norms embedded in the individual's self-understanding. Health promotion focuses on factors such as diet, smoking, alcohol and exercise, where the body is optimized as a physical framework and where it is important to lead a healthy life as an end in itself. However, rather than telling people what a healthy life is, we as healthcare professionals perhaps need to step back and tone down our health ideals and instead look at what a good life means for each individual person. If we look at human history, we can see that being part of a social community is something that has created far better conditions for a healthy life, and that it stands in contrast to an egocentric project, where the only important 
thing is to optimize physical fitness. In this regard, Missel et al. (2019) have pointed out that precisely a sense of community and understanding can be established for patients who participate in exercise, with exercise facilitating community and increasing social capital.

\section{Study Strengths and Limitations}

Phenomena can be viewed from many possible perspectives and a full understanding of any given phenomenon, such as non-participation in exercise, is not considered possible. There can be no saturation point and no final analysis (Gerrish \& Lathlean, 2015); the inquiry is circular and the exploration of non-participation in exercise for people after lung cancer surgery does not end with this paper. This article has nonetheless contributed by providing a greater sense of awareness and increasing sensitivity towards why patients might refuse participating in rehabilitation following lung cancer surgery. The validity of phenomenological findings is not based on their ability to correspond perfectly to all cases, but rather that they have sufficient coherence to be meaningfully applied to similar situations (Dahlberg, Dahlberg, \& Nytröm, 2008; van Wijngaarden, Meide, \& Dahlberg, 2017). The reader should take this aspect into account when transferring the findings to other surgical lung cancer patients. It is also important to note that data originates from a study conducted in a Danish context, and not all countries, societies and cultures share the same perspectives on physical exercise.

One of the strengths of this study is that the data was gathered from participants who had the ability to describe their perceptions, considerations and attitudes toward non-participation in rehabilitation. They were willing and able to give descriptions of their own personal experiences, providing rich personal accounts. This enabled an in-depth and trustworthy analysis (Crabtree \& Miller, 1999). Moreover, the inclusion of direct participant quotes 
ensures transparency and substantiates the findings of the study. In phenomenological research, bridling the researchers' preunderstanding is, according to Dahlberg et al. (2008), an essential aspect of ensuring a study's internal validity. The prior knowledge of researchers can lead to important subtleties being overlooked during the interview process. We worked to minimize this eventuality by actively using strategies in the research process to create distance and to allow space for being curious. For example, the interviews focused on the participants' accounts rather than proceeding from preconceptions, just as researcher triangulation in the data analysis process was used and two well-qualified researchers conducted the interviews (Crabtree \& Miller, 1999).

\section{Conclusions}

For participants in this study, their lived experiences, perceptions and considerations concerning non-participation in rehabilitation involved more than whether a change in health behavior, such as exercise, would lead to better health. They include many aspects of the individual participant's assessment and own perception of the good or the meaningful life. The meaning of participating in rehabilitation after surgery for lung cancer is affected by the discrepancies that arise between freedom and necessity. The participants are affected by their own values and individual perceptions of the good life, as well as their social network, which means that the measurable benefits of participation in exercise are not the only influencing factor. As such, exercise can create a dissonance in the patients, leading to a questioning of some of the basic, underlying assumptions of the patients' lifeworld.

The participants' perceptions of participation in exercise are also influenced by society and societal norms regarding physical activity, which is considered a correct health behavior. This may mean that patients might perceive health and rehabilitation as their own responsibility. 
However, health behavior is not just individually driven, and health is created beyond the individual level. The individual person's underlying narrative about values and the good life, their balance between priorities in daily life, their social context and relationships in which they live their life and norms embedded in their self-understanding are crucial to gain insight into when to recommend lifestyle changes and include people in rehabilitation after lung cancer surgery.

\section{Declaration of Conflicting Interests}

The authors have no conflicting interests.

\section{Funding}

The study was funded by the Centre for Integrated Rehabilitation of Cancer patients (CIRE), which was established and is supported by the Danish Cancer Society and the Novo Nordisk Foundation.

Table I. Interview Guide

\begin{tabular}{|c|c|}
\hline Topic & Interview Questions \\
\hline $\begin{array}{l}\text { Opening / daily life } \\
\text { experiences }\end{array}$ & $\begin{array}{l}\text { Can you talk a little about how you are doing and how you feel? } \\
\text { How do you spend your time in your daily life? }\end{array}$ \\
\hline $\begin{array}{l}\text { Changes in health } \\
\text { since surgery }\end{array}$ & $\begin{array}{l}\text { Can you talk about how you have been doing since your surgery and up to now? } \\
\text { What has been most difficult or challenging? } \\
\text { How does that affect you daily life? } \\
\text { Do you experience any limitations in your daily life due to your illness and surgery? } \\
\text { And, if so, how do such limitations affect daily life and tasks? } \\
\text { Is there anything in your life that has changed in any way due to illness and surgery? } \\
\text { In what way do the changes manifest themselves? } \\
\text { Can you talk about what you have done to get back on track after the surgery? } \\
\text { What has motivated you? }\end{array}$ \\
\hline $\begin{array}{l}\text { Relatives / social } \\
\text { relationships }\end{array}$ & $\begin{array}{l}\text { Can you talk a little about your social relationships? } \\
\text { How do you experience your relationships with family and friends and how would } \\
\text { you describe these relationships? } \\
\text { Have there been any changes in your relationships with family and friends after you } \\
\text { became ill and underwent surgery? In what way? } \\
\text { How do you feel about that? }\end{array}$ \\
\hline
\end{tabular}




\begin{tabular}{|c|c|}
\hline & $\begin{array}{l}\text { Are there any things you cannot talk to your family and friends about? How do you } \\
\text { feel about that? }\end{array}$ \\
\hline $\begin{array}{l}\text { Physical activity / } \\
\text { exercise }\end{array}$ & $\begin{array}{l}\text { How do you feel about physical activity? } \\
\text { Do you do any kind of exercise? What kind(s)? } \\
\text { Do you think exercise is/would be good for you and your health? In what way? } \\
\text { Did you do any kind of physical activity or exercise before your illness and surgery? } \\
\text { What kind(s)? What did it mean to you? How did you feel about it? } \\
\text { Have you participated in any rehabilitation or exercise after surgery? What kind(s)? } \\
\text { Have you participated in a team/group or individually? Can you talk more about } \\
\text { that? }\end{array}$ \\
\hline $\begin{array}{l}\text { Declined to participate } \\
\text { in PROLUCA } \\
\text { rehabilitation trial }\end{array}$ & $\begin{array}{l}\text { When you had surgery, you were asked if you would like to be part of a project after } \\
\text { the surgery that involved participating in team exercise at a cancer rehabilitation } \\
\text { center. You did not wish to participate. Could you please talk about what your } \\
\text { considerations were when you said no? } \\
\text { If you think back to the time since your surgery, do you wish you would have said } \\
\text { yes? Why/why not? } \\
\text { Can you describe what it would take for you to sign up for a project like that? }\end{array}$ \\
\hline $\begin{array}{l}\text { Support from the } \\
\text { healthcare system / } \\
\text { closing remarks }\end{array}$ & $\begin{array}{l}\text { Have you experienced any lack of support or information from the healthcare } \\
\text { system? In what way? What kind of support or information was lacking and how did } \\
\text { that affect you? } \\
\text { Is there anything in your contact with the healthcare system that you wish could } \\
\text { have been different? What and in what way? } \\
\text { Given your experiences, can you think of any support that would have been helpful } \\
\text { to you? }\end{array}$ \\
\hline
\end{tabular}




\section{References}

Adamsen, L., Quist, M., Andersen, C., Moller, T., Herrstedt, J., Kronborg, D., ... Rorth, M. (2009). Effect of a multimodal high intensity exercise intervention in cancer patients undergoing chemotherapy: randomised controlled trial. $B M J, 339, \mathrm{~b} 3410$. doi.org/10.1136/bmj.b3410

Anand, S. (2002). The concern for equity in health. Journal of Epidemiology and Community Health, 56(7), 485-487. doi.org/10.1136/jech.56.7.485

Arbane, G., Tropman, D., Jackson, D., \& Garrod, R. (2011). Evaluation of an early exercise intervention after thoracotomy for non-small cell lung cancer (NSCLC), effects on quality of life, muscle strength and exercise tolerance: randomised controlled trial. Lung Cancer, 71(2), 229-234. doi.org/10.1016/j.lungcan.2010.04.025

Aristotle. (2004). Poetikken [Poetics]. Denmark, Copenhagen: Det Lille Forlag.

Bade, B. C., Thomas, D. D., Scott, J. B., \& Silvestri, G. A. (2015). Increasing physical activity and exercise in lung cancer: reviewing safety, benefits, and application. Journal of Thoracic Oncology, 10(6), 861-871. doi.org/10.1097/JTO.0000000000000536

Bandura, A. (2004). Health Promotion by Social Cognitive Means. Health Educ Behav 31(2):143-164.

Bell, K. (2017). Health and other unassailable values: reconfigurations of health, evidence and ethics. Routledge, New York USA.

Bremer, A., Dahlberg, K., \& Sandman, L. (2009). Experiencing Out-of-Hospital Cardiac Arrest: Significant Others' Lifeworld Perspective. Qualitative Health Research, 19(10), 1407-1420. doi.org/10.1177/1049732309348369

Cavalheri, V., Tahirah, F., Nonoyama, M., Jenkins, S., \& Hill, K. (2014). Exercise training for people following lung resection for non-small cell lung cancer - a Cochrane systematic review. Cancer Treatment Reviews, 40(4), 585-594. doi.org/10.1016/j.ctrv.2013.11.001

Coups, E. J., Park, B. J., Feinstein, M. B., Steingart, R. M., Egleston, B. L., Wilson, D. J., \& Ostroff, J. S. (2009). Physical activity among lung cancer survivors: changes across the cancer trajectory and associations with quality of life. Cancer Epidemiology, Biomarkers \& Prevention, 18(2), 664-672. doi.org/10.1158/1055-9965.EPI-08-0589

Crabtree Miller,W.L., B. F. (1999). Doing Qualitative Research (2nd ed.). California, UK, India: Sage Publication.

Crandall, K., Maguire, R., Campbell, A., \& Kearney, N. (2014). Exercise intervention for patients surgically treated for non-small cell lung cancer (NSCLC): a systematic review. Surgical Oncology, 23(1), 17-30. doi.org/10.1016/j.suronc.2014.01.001

Dahlberg, K., Dahlberg, H., \& Nytröm, M. (2008). Refelctive Life Research (Second ed.). Sweden, Lund: Studentlitteratur.

de Sousa, R. (2003). Paradoxical Emotion: On Sui Generis Emotional Irrationality. In Weakness of Will and Practical Irrationality, Oxford University Press, Oxford, United Kingdom: (pp. 274-297). doi.org/10.1093/0199257361.003.0012

Demark-Wahnefried, W., Aziz, N. M., Rowland, J. H., \& Pinto, B. M. (2005). Riding the crest of the teachable moment: promoting long-term health after the diagnosis of cancer. Journal of Clinical Oncology, 23(24), 5814-5830. doi.org/JCO.2005.01.230

Diderichsen, F; Andersen, I; Manuel, C. (2011). Ulighed i sundhed - årsager og indsatser [Inequality in health - causes and efforts]. Retrieved from http://www.sst.dk

Gadamer, H.-G. 1900-2002 (2004). Truth and Method: Continuum impacts. 2nd ed. London, UK: Continuum.

Garber, C. E., Blissmer, B., Deschenes, M. R., Franklin, B. A., Lamonte, M. J., Lee, I. M., ... Medicine, A. C. (2011). American College of Sports Medicine position stand. Quantity and quality of exercise for developing and maintaining cardiorespiratory, musculoskeletal, and neuromotor fitness in apparently healthy adults: guidance for 
prescribing exercise. Medicine and Science in Sports and Exercise, 43(7), 1334-1359. doi.org/10.1249/MSS.0b013e318213fefb

Gerber, M., \& Pühse, U. (2009). Review Article: Do exercise and fitness protect against stress-induced health complaints? A review of the literature. Scandinavian Journal of Public Health, Vol. 37, pp. 801-819. doi.org/10.1177/1403494809350522

Granger, C. L., McDonald, C. F., Berney, S., Chao, C., \& Denehy, L. (2011). Exercise intervention to improve exercise capacity and health related quality of life for patients with Non-small cell lung cancer: a systematic review. Lung Cancer, 72(2), 139-153. doi.org/10.1016/j.lungcan.2011.01.006

Handy Jr, J. R., Asaph, J. W., Skokan, L., Reed, C. E., Koh, S., Brooks, G., ... Silvestri, G. A. (2002). What happens to patients undergoing lung cancer surgery? Outcomes and quality of life before and after surgery. Chest, 122(1), 21-30.

Henshall, C., Greenfield, S., \& Gale, N. (2017). The Role of Self-Management Practices as Mechanisms for Re-Establishing Normality in Cancer Survivors. Qualitative Health Research, 27(4), 520-533. doi.org/10.1177/1049732316651252

Hoffmann, T. (2008). Weakness of will from Plato to the present. The Catholic University of America Press.

Horrocks, C., \& Johnson, S. (2014). A Socially Situated Approach to Inform Ways to Improve Health and Wellbeing. Sociology of Health \& Illness Vol. 36 No. 2:175-186. doi: $10.1111 / 1467-9566.12114$

Jones, L. W., Eves, N. D., Spasojevic, I., Wang, F., \& Il'yasova, D. (2011). Effects of aerobic training on oxidative status in postsurgical non-small cell lung cancer patients: a pilot study. Lung Cancer, 72(1), 45-51. doi.org/10.1016/j.lungcan.2010.08.002

Kampshoff, C. S., Jansen, F., van Mechelen, W., May, A. M., Brug, J., Chinapaw, M. J. M., \& Buffart, L. M. (2014). Determinants of exercise adherence and maintenance among cancer survivors: A systematic review. International Journal of Behavioral Nutrition and Physical Activity, Vol. 11. doi.org/10.1186/1479-5868-11-80

Kenny, P. M., King, M. T., Viney, R. C., Boyer, M. J., Pollicino, C. A., McLean, J. M., ... McCaughan, B. C. (2008). Quality of life and survival in the 2 years after surgery for non small-cell lung cancer. Journal of Clinical Oncology, 26(2), 233-241. doi.org/JCO.2006.07.7230

Levin, J., Milgrom, P., \& Rangel, A. (2004). Introduction to Choice Theory 1 Individual Decision-Making. Stanford University.

Martinez, J. V., Oberle, C. D., \& Nagurney, A. J. (2013). Basic Psychological Needs in Predicting Exercise Participation. Advances in Physical Education, 3(1), 20-27. doi.org/10.4236/ape.2013.31004

McCance, T. V, McKenna, H. P., \& Boore, J. R. (2001). Exploring caring using narrative methodology: an analysis of the approach. Journal of Advanced Nursing, 33(3), 350356. doi.org/jan1671

Midtgaard, J., Stage, M., Moller, T., Andersen, C., Quist, M., Rorth, M., ... Adamsen, L. (2011). Exercise may reduce depression but not anxiety in self-referred cancer patients undergoing chemotherapy. Post-hoc analysis of data from the "Body \& Cancer" trial. Acta Oncologica, 50(5), 660-669. doi.org/10.3109/0284186X.2010.543145

Mills, A. L., \& Pierce, J. P. (2008). Using teachable moments to improve nutrition and physical activity in patients. American Family Physician, 77(11), 1510-1512.

Mishra, S. I., Scherer, R. W., Snyder, C., Geigle, P. M., Berlanstein, D. R., \& Topaloglu, O. (2012). Exercise interventions on health-related quality of life for people with cancer during active treatment. Clinical Otolaryngology, 37(5), 390-392. doi.org/10.1111/coa.12015

Missel, M., Borregaard, B., Schoenau, M. N., \& Sommer, M. S. (2019). A sense of understanding and belonging when life is at stake-Operable lung cancer patients' lived experiences of participation in exercise. European Journal of Cancer Care, e13126. 
doi.org/10.1111/ecc.13126

Missel, M., Pedersen, J. H., Hendriksen, C., Tewes, M., \& Adamsen, L. (2015). Exercise intervention for patients diagnosed with operable non-small cell lung cancer: a qualitative longitudinal feasibility study. Supportive Care in Cancer, 23(8). doi.org/10.1007/s00520-014-2579-3

Missel, M., Pedersen, J. H., Hendriksen, C., Tewes, M., \& Adamsen, L. (2016). Regaining familiarity with own body after treatment for operable lung cancer - a qualitative longitudinal exploration. European Journal of Cancer Care, 25(6), 1076-1090. doi.org/10.1111/ecc.12383

Moller, T., Lillelund, C., Andersen, C., Ejlertsen, B., Norgaard, L., Christensen, K. B., ... Adamsen, L. (2013). At cancer diagnosis: a "window of opportunity" for behavioural change towards physical activity. A randomised feasibility study in patients with colon and breast cancer. BMJ Open, 3(11), 3556. doi.org/10.1136/bmjopen-2013-003556

Mushkin, P., Band-Winterstein, T., \& Avieli, H. (2018). “Like Every Normal Person?!” The Paradoxical Effect of Aging With Schizophrenia. Qualitative Health Research, 28(6), 977-986. doi.org/10.1177/1049732318764389

Oksholm, T., Rustoen, T., Cooper, B., Paul, S. M., Solberg, S., Henriksen, K., ... Miaskowski, C. (2015). Trajectories of Symptom Occurrence and Severity from Before Through Five Months After Lung Cancer Surgery. Journal of Pain and Symptom Management. doi.org/S0885-3924(15)00031-7

Ormel, H. L., van der Schoot, G. G. F., Sluiter, W. J., Jalving, M., Gietema, J. A., \& Walenkamp, A. M. E. (2018). Predictors of adherence to exercise interventions during and after cancer treatment: A systematic review. Psycho-Oncology, Vol. 27, pp. 713724. doi.org/10.1002/pon.4612

Pedersen, B. K., \& Saltin, B. (2015). Exercise as medicine - Evidence for prescribing exercise as therapy in 26 different chronic diseases. Scandinavian Journal of Medicine and Science in Sports, 25, 1-72. doi.org/10.1111/sms.12581

Petersen A, Lupton, D. (2000). The New Public Health: Discourses, Knowledges, Strategies. London, Thousand Oaks, New Dehli, SAGE Publications, Great Britain

Quist, M., Sommer, M. S., Vibe-Petersen, J., Stærkind, M. B., Langer, S. W., Larsen, K. R., ... Pedersen, J. H. (2018). Early initiated postoperative rehabilitation reduces fatigue in patients with operable lung cancer: A randomized trial. Lung Cancer. doi.org/10.1016/j.lungcan.2018.10.025

Rasmussen, T. R., \& Jakobsen, E. (2013). Danish Lung Cancer Group and Danish Lung Cancer Registry. Retrieved from http://www.lungecancer.dk

Real, K., \& Rimal, R. N. (2005). How Behaviors are Influenced by Perceived Norms: A Test of the Theory of Normative Social Behavior. Communication Research, 32(3), 389-414

Rogers, L. Q., \& Tudor-Locke, C. (2006). Physical activity reactivity: More questions than answers [2]. Measurement in Physical Education and Exercise Science, Vol. 10, pp. 269-271. doi.org/10.1207/s15327841mpee1004_5

Sarna, L., Cooley, M. E., Brown, J. K., Chernecky, C., Elashoff, D., \& Kotlerman, J. (2008). Symptom severity 1 to 4 months after thoracotomy for lung cancer. American Journal of Critical Care, 17(5), 67;468. doi.org/17/5/455

Sommer, M. S., Trier, K., Vibe-Petersen, J., Christensen, K. B., Missel, M., Christensen, M., ... Langberg, H. (2016). Changes in Health-Related Quality of Life During Rehabilitation in Patients With Operable Lung Cancer: A Feasibility Study (PROLUCA). Integrative Cancer Therapies. doi.org/10.1177/1534735416668258

Sommer, M. S., Trier, K., Vibe-Petersen, J., Missel, M., Christensen, M., Larsen, K. R., ... Langberg, H. (2014). Perioperative rehabilitation in operation for lung cancer (PROLUCA) - rationale and design. BMC Cancer, 14(1), 404. doi.org/10.1186/14712407-14-404

Sommer, M. S., Trier, K., Vibe-Petersen, J., Missel, M., Christensen, M., Larsen, K. R., ... 
Langberg, H. (2016). Perioperative Rehabilitation in Operable Lung Cancer Patients (PROLUCA): A Feasibility Study. Integrative Cancer Therapies, 15(4). doi.org/10.1177/1534735416635741

Sommer, M., Staerkind, M., Christensen, J., Vibe-Petersen, J., Larsen, K., Pedersen, J., \& Langberg, H. (2018). Effect of postsurgical rehabilitation programmes in patients operated for lung cancer: A systematic review and meta-analysis. Journal of Rehabilitation Medicine, 50(3), 236-245. doi.org/10.2340/16501977-2292

Sundler, A. J., Dahlberg, K., \& Ekenstam, C. (2009). The Meaning of Close Relationships and Sexuality: Women's Well-Being Following a Myocardial Infarction. Qualitative Health Research, 19(3), 375-387. doi.org/10.1177/1049732309331882

van Wijngaarden, E., Meide, H. van der, \& Dahlberg, K. (2017). Researching Health Care as a Meaningful Practice: Toward a Nondualistic View on Evidence for Qualitative Research. Qualitative Health Research, 27(11), 1738-1747. doi.org/10.1177/1049732317711133

World Health Organization (WHO) (2018). Social inequalities in environment and health. Retrieved from http://www.euro.who.int/en/health-topics/environment-andhealth/social-inequalities-in-environment-and-health 